\title{
Left ventricular dysfunction in preeclampsia: an echocardiographic study
}

\section{Subha Sivagami Sengodan*, Mohana Dhanapal, Anbarasi Pandian}

Department of Obstetrics and Gynecology, Government Mohankumarmangalam Medical College, Salem, Tamil Nadu, India

Received: 27 July 2017

Revised: 18 September 2017

Accepted: 25 September 2017

*Correspondence:

Dr. Subha Sivagami Sengodan,

E-mail: drppsamysubha@gmail.com

Copyright: ( ) the author(s), publisher and licensee Medip Academy. This is an open-access article distributed under the terms of the Creative Commons Attribution Non-Commercial License, which permits unrestricted non-commercial use, distribution, and reproduction in any medium, provided the original work is properly cited.

\section{ABSTRACT}

Background: Preeclampsia is a pregnancy specific disorder which constitutes hypertension and proteinuria after 20 weeks of gestation. It is a multisystem disorder of unknown etiology. Preeclampsia is associated with significantly higher prevalence of asymptomatic global left ventricular function and myocardial injury than uneventful pregnancy. This study was undertaken to evaluate the Left ventricular changes in preeclamptic women and to compare with normotensive women.

Methods: This prospective study on left ventricular systolic and diastolic function by echocardiography was undertaken in normal and preeclamptic pregnant women who got admitted during the period of one year from January 2015 to December 2015 at Government Mohan Kumaramangalam Medical College and Hospital, Salem. Study population was divided into two groups. GROUP 1-Preeclamptic pregnant women GROUP 2-Normotensive pregnant women as control.

Results: There were significant differences in the mean end diastolic dimensions when compared to systolic dimension between two groups.

Conclusions: Women with preeclampsia have significant systolic and diastolic dysfunction compared to normotensive pregnant women. Effective management of patients who showed left ventricular dysfunction prevented pulmonaryedema and cardiac failure. This study emphasizes the importance of identifying this subset of preeclamptic patients with ECHO changes who are at higher risk of developing cardiovascular complications later in life by undergoing echocardiography.

Keywords: Diastolic dysfunction, Echocardiography, Preeclampsia, Systolic dysfunction

\section{INTRODUCTION}

Preeclampsia is an acute increase in blood pressure during the second half of pregnancy which is short-lived. More than $50 \%$ of the women with elevated blood pressure during pregnancy return to normal by 6-12 weeks postpartum. In developing countries preeclampsia ranks second to anaemia as a cause of maternal morbidity and mortality complicating $7-10 \%$ of all pregnancies.
Preeclampsia is associated with both immediate and long term postpartum morbidity and mortality due to cardiac related issues. ${ }^{1}$ The pathological changes in this disorder are primarily ischemic in nature and are known to affect the placenta, kidney, liver and brain whereas there is scant and conflicting information about the impact on heart. Preeclampsia causes left ventricle dysfunction and myocardial injury. Significant proportion of preeclamptic patients show cardiopulmonary morbidity and autopsy 
data have a 10-fold higher prevalence of myocardial contraction and band necrosis than deaths in pregnancy due to other causes. A pregnancy complicated by preeclampsia identifies both mother and child with an unusual predisposition to develop cardio vascular diseases. $^{2,3}$ Cardiac failure with pulmonary edema may occur in hypertensive patients with normal heart. Preeclampsia is a recognised predisposing factor for peripartum cardiomyopathy and future cardiovascular disease. This prospective study on left ventricular systolic and diastolic function by echocardiography was undertaken in normal and preeclamptic pregnancies. Even in clinically asymptomatic preeclamptic patients, subtle echocardiographic changes in left ventricular function has been observed.

\section{METHODS}

Patients with preeclampsia who have been admitted in the antenatal ward over the period of one year from January 2015 to December 2015 at Government Mohankumaramangalam Medical College and Hospital, Salem were the subjects of the study. This case control study included 200 women in each group - 200 patients with preeclampsia as cases and 200 normotensive patients as control. Preeclampsia is defined as new onset hypertension of $140 / 90 \mathrm{~mm} \mathrm{Hg}$ or more and 24 hour proteinuria of $0.3 \mathrm{~g}$ or more, occurring after 20 weeks of gestation. Blood Pressure was checked with mercury sphygmomanometer with appropriate cuff size with patient in sitting position with arm at the level of heart. Echo was performed with patients in left lateral position.

\section{Inclusion criteria}

- Patients with mild Pre eclampsia which was diagnosed when there is a sustained systolic blood pressure of $140 \mathrm{mmHg}$ or more, and or a diastolic blood pressure of $90 \mathrm{~mm} \mathrm{Hg}$ or more present on two or more occasions atleast six hours apart occurring after 20 weeks of gestation associated with proteinuria of $>0.3 \mathrm{gm}$ protein in a 24 hours urine sample or $>30 \mathrm{mg} / \mathrm{dl}$ or $1+$ on dipstick in random urine sample.

- Patients with severe Preeclampsia which was diagnosed when blood pressure was $160 / 110 \mathrm{mmHg}$ or proteinuria of $>5 \mathrm{gm} / 24$ hours or more.

- $\quad$ Age 18 to 35 years

- Gestational age 28 to 36 weeks.

\section{Exclusion criteria}

- Patients with pre existing hypertension

- Patients with known cardiorespiratory disease, renal disease, connective tissue disorders

- Patients with anaemia

- Patients with gestational diabetes mellitus

- Patients in labour

- Twin pregnancy

- Alcohol and Tobacco usage.

\section{Echocardiographic studies}

All patients were examined by a cardiologist using echo machine with $2.5 \mathrm{mHz}$ transducer at the Department of Cardiology, Government Mohan Kumaramangalam Medical College Hospital, Salem. Echocardiography of left ventricle was obtained under standard conditions during quiet expiration with patients in the left lateral recumbent positions after the patients remained undisturbed in this position for 15 minutes.

\section{Measurements}

M-mode, 2D and Doppler echocardiographic evaluation were performed in all patients in the standard left parasternal axis view with continuous ECG gating according to the ASE guidelines. Initial $2 \mathrm{D}$ studies were done to evaluate cardiac structure and visual assessment of Left Ventricle contractile function. M-mode studies were performed at the level of aorta, left atrium and left ventricle. Doppler flow was recorded across the mitral valve to obtain left ventricle diastolic filling pattern.

Systolic parameters studied were: Left Ventricle end systolic volume (LVESV), Stroke volume (SV), Cardiac output (CO), Ejection Fraction (EF), Aortic root diameter (ARD), Left ventricular outflow tract (LVOT) and left ventricular mass (LVM).

\section{$\mathrm{EF}=\mathrm{EDV}-\mathrm{ESV} / \mathrm{EDV} \times 100$}

\section{Normal: 50 to $75 \%$}

Diastolic parameters studied were: $\mathrm{E}$ wave, A wave, E/A ratio, isovolumetric relaxation time (IVRT), $\mathrm{E}$ deceleration time (DtE), E wave velocity time integral (E VTI) and A wave velocity time integral (A VTI).

E/A ratio: early filling / filling due to atrial contraction.

\section{Normal 0.8 to 2}

Iso Volumetric Relaxation Time Time interval between closure of aortic valve and opening of mitral valve. Normal 73 to $110 \mathrm{~ms}$. More than $110 \mathrm{~ms}$ is considered as prolonged IVRT indicative of diastolic dysfunction.

\section{Deceleration time (DT)}

Time taken for left atrial and left ventricular pressures to equilibrate. Normal 160 to $230 \mathrm{~ms}$. Prolonged in diastolic dysfunction.

\section{RESULTS}

Table 1 shows the baseline features of study population. Age and BMI were similar in the two groups. Differences in Systolic BP, Diastolic BP and Mean Arterial Pressure (MAP) were statistically significant between the two 
groups. MAP in preeclamptic women was $95-125 \mathrm{~mm} \mathrm{Hg}$, higher than that of control 77-89 $\mathrm{mm} \mathrm{Hg}$.

Table 1: Baseline characteristics of two study groups.

\begin{tabular}{|lll|}
\hline Parameter & $\begin{array}{l}\text { Normotensive } \\
(\mathrm{N}=200)\end{array}$ & $\begin{array}{l}\text { Preeclamptic } \\
(\mathrm{N}=200)\end{array}$ \\
\hline AGE (in years) & $23-27$ & $22-28$ \\
\hline BMI $\left(\mathrm{kg} / \mathrm{m}^{2}\right)$ & $18-26$ & $20-34$ \\
\hline Systolic BP $(\mathrm{mm} \mathrm{Hg})$ & $87-133$ & $143-167$ \\
\hline Diastolic BP $(\mathrm{mm} \mathrm{Hg})$ & $63-74$ & $85-105$ \\
\hline MAP $(\mathrm{mm} \mathrm{Hg})$ & $77-89$ & $95-125$ \\
\hline
\end{tabular}

Table 2 shows comparison of systolic parameters between two study groups. Cardiac Output in the preeclamptic group was $62-70$ as compared to $54-57$ in the normotensive group. This observation was statistically significant. Left ventricular Diastolic mass was significantly higher in preeclamptic patients when compared to Left ventricular systolic mass. Left Ventricular Systolic Volume was significantly higher in preeclamptic when compared to Left Ventricular Diastolic Volume.

Table 2: Comparison of systolic parameters between two groups.

\begin{tabular}{|ll|l|}
\hline Parameter & Normotensive & Preeclamptic \\
\hline CO $(\mathrm{ml} / \mathrm{min})$ & $54-57$ & $62-70$ \\
\hline LVESV(ml) & $24-30$ & $23-49$ \\
\hline LVEDV $(\mathrm{ml})$ & $102-112$ & $81-135$ \\
\hline LVMS $(\mathrm{gm})$ & $60-106$ & $81-95$ \\
\hline LVMD $(\mathrm{gm})$ & $81-127$ & $115-147$ \\
\hline
\end{tabular}

Table 3 shows comparison of diastolic parameters between normotensive and preeclamptic patients. E wave velocity, A wave velocity, IVRT, E wave deceleration time and A VTI were higher in preeclamptic patients.

Table 3: Comparison of diastolic parameters between two study groups.

\begin{tabular}{|lll|}
\hline Parameters & Normotensive & Preeclamptic \\
\hline E wave $(\mathrm{m} / \mathrm{s})$ & $0.538-0.812$ & $0.831-1.215$ \\
\hline A wave $(\mathrm{m} / \mathrm{s})$ & $0.370-0.630$ & $0.497-1.053$ \\
\hline E/A ratio & $1.13-1.57$ & $1.005-1.989$ \\
\hline DtE $(\mathrm{ms})$ & $118.2-134$ & $139.9-238.1$ \\
\hline IVRT $(\mathrm{ms})$ & $78.3-89.2$ & $87-105.26$ \\
\hline E VTI $(\mathrm{ms})$ & $10.44-14.24$ & $9.31-17.53$ \\
\hline A VTI $(\mathrm{ms})$ & $2.09-3.35$ & $5.39-7.47$ \\
\hline
\end{tabular}

\section{DISCUSSION}

Preeclampsia contributes substantially to maternal and fetal morbidity and mortality. Angiogenic imbalance with high circulating levels of antiangiogenic proteins such as soluble fms like tyrosinekinase -1 (sFlt-1) and soluble endoglin is found in women with preeclampsia. ${ }^{4}$ Sensitive marker for diastolic dysfunction is sFlt 1which is also pathognomonic for peripartum cardiomyopathy. Angiogenic imbalance which is the hallmark of preeclampsia resolves after pregnancy but the cardiac changes persist for a year. ${ }^{5}$ Due to increase in peripheral vascular resistance as preeclampsia evolves there is significant drop in cardiac output. ${ }^{6,7}$ Patients with Preeclampsia show left ventricular hypertrophy and regional longitudinal systolic dysfuction due to subendocardial ischemia and/or fibrosis in the longitudinal myocardial fibers. ${ }^{8}$ In this study, Echocardiography has been used to demonstrate reduced cardiac diastolic function when compared to systolic function. ${ }^{9}$ In normal pregnancy, an increased preload and a decreased afterload favour an improved emptying of the left ventricle during systole and reduction of End Systolic Pressure. In preeclamptic women, the elevated afterload is linked with a reduced emptying of the left ventricle and elevated End Systolic Pressure.

In present study, we found the mean LVESV was 23$49 \mathrm{ml}$ in preeclamptic women when compared to $24-30 \mathrm{ml}$ in normotensives. The mean LVEDV was $81-135 \mathrm{ml}$ in preeclamptic when compared to $102-112 \mathrm{ml}$ in normotensives. The LVMD was $115-147 \mathrm{gm}$ in preeclamptic when compared to $81-127 \mathrm{gm}$ in normotensives. The mean IVRT was $87-105.26 \mathrm{~ms}$ in preeclamptic when compared to $78.3-89.2 \mathrm{~ms}$ in normotensives. The mean $\mathrm{E}$ wave velocity was 0.831 $1.215 \mathrm{~m} / \mathrm{s}$ in preeclamptic when compared to $0.538-0.812$ $\mathrm{m} / \mathrm{s}$ in normotensives. The mean A wave velocity was $0.497-1.053 \mathrm{~m} / \mathrm{s}$ in preeclamptic when compared to 0.370 $0.630 \mathrm{~m} / \mathrm{s}$ in normotensives. All these suggest the significance of diastolic dysfunction. Due to increased total peripheral resistance in preeclampsia there is an increase in afterload and the left ventricle becomes stiff. This may be the possible mechanism by which diastolic dysfunction develops independent of left ventricular hypertrophy.

\section{CONCLUSION}

This study shows that there are significant cardiovascular dynamic changes in subjects with preeclampsia which can be studied with Echo and they are at higher risk of developing cardiovascular complications later in life. Women with preeclampsia have significant systolic and diastolic dysfunction when compared to normotensive pregnant women. Appropriate management of the patients who showed left ventricular dysfunction prevented pulmonary edema and cardiac failure. The data on changes in left ventricular diastolic dysfunction is scarce. Hence this exploratory study assessed the various hemodynamic alterations in preeclampsia during second half of pregnancy, on echocardiography very clearly and found it to be a useful technique. Doppler imaging studies of myocardial function in women, following a preeclamptic pregnancy, is of value to define the long term clinical relevance of the disease process. BP monitoring alone is insufficient to identify effectively, the risk of complications. Maternal Echo can be introduced 
into routine investigation protocol, which could help to identify women who are at high risk of developing cardiovascular complications. Patients can even be followed during the postpartum period to examine whether the altered hemodynamic state reverts to normal after pregnancy.

Funding: No funding sources Conflict of interest: None declared

Ethical approval: The study was approved by the Institutional Ethics Committee

\section{REFERENCES}

1. Bauer ST, Clearly KL. Cardiopulmonary complications of preeclampsia. Semin Perinatol. 2009;33:158-165.

2. Bellamy L, Casas JP, Hingorani AD, WilliamsDJ. Pre-eclampsia and risk of cardiovascular disease disease and cancer in later in life:systematic view and meta-analysis. BMJ. 2007;335:974.

3. Davis EF, Lazdam M, Lewandowski AJ, Worton SA, Kelly B, Ken-worthy $\mathrm{Y}$ et al. Cardiovascular risk factors in children and young adults born to preeclampticpregnancies: a systematic review. Pediatrics. 2012;129:e1552-e1561.

4. Bauer TW, Moore GW, Hutchins GM. Morphologic evidence for coronary artery spasm in eclampsia. Circulation. 1982;65:255-9.
5. Melchiorre K, Sutherland GR, Liberati M, Thilaganathan B. Preeclampsia is associated with persistent postpartum cardiovascular impairment. Hypertension. 2011;58:709-715.

6. Jio RZ, Liu XM, Wang X, Wu HQ. Relationship between cardiovascular function and fetal growth restriction in women with pre-eclampsia. Int $\mathbf{J}$ Gynecol Obstet. 2010;110:61-63.

7. Bamfo JE, Kametas NA, Chambers JB, Nicolaides $\mathrm{KH}$. Maternal cardiac function in normotensive and pre eclamptic intra uterine growth restriction. Ultra sound. Obstet Gynecol. 2008:32:682-6.

8. Bijnes BH, Cikes M, Claus P, Sutherland GR. Velocity and deformation imaging for the assessment of myocardial dysfunction.Eur $\mathrm{J}$ Echo cardiogr. 2009;10:216-226.

9. Rafik Hamad R, Larsson A, Pernow J, Bremme K, Eriksson MJ. Assessment of left ventricular structure and function in preeclampsia by echocardiography and cardio vascular biomarkers. J Hypertens. 2009;27:2257-64.

Cite this article as: Sengodan SS, Dhanapal M, Pandian A. Left ventricular dysfunction in preeclampsia: an echocardiographic study. Int J Reprod Contracept Obstet Gynecol 2017;6:4895-8. 